\title{
Quality of hypertension treatment and risk of stroke in the general population Olaf $\mathrm{H}$. Klungel
}

Journal of Hypertension 2002, 20:1949-1950

Department of Pharmacoepidemiology and Pharmacotherapy, Utrecht Institute of Pharmaceutical Sciences (UIPS), Universiteit Utrecht, Utrecht, The Netherlands.

Correspondence and requests for reprints to Olaf H. Klungel, Department of Pharmacoepidemology and Pharmacotherapy, Faculty of Pharmaceutical Sciences, Universiteit Utrecht, PO Box 80082, 3508 TB Utrecht, The Netherlands.

Tel: +31 30 2537324; fax: +3130 2539166; e-mail: o.h.klungel@pharm.uu.nl

\section{See original paper on page 2081}

It has long been observed that target blood pressure levels are not achieved in many hypertensive patients, despite drug treatment, and that many receive no drug treatment at all. This observation lead to the introduction of the so called 'rule of halves' (half of the hypertensives are detected, half of which are treated, of which only half achieves adequate blood pressure control) by Wilber and Barrow in 1972 [1]. During the past decades, many population studies from different countries have confirmed these observations. Although awareness and treatment of hypertension have improved, still only half of the treated hypertensives achieve sufficient blood pressure control [2]. These observations should be perceived from the perspective of the limitations that many of these studies share. In most studies, blood pressure is only measured once or twice during a single visit. Due to the substantial within-person variability in blood pressure, prevalences of hypertension are overestimated, whereas prevalence of treatment of hypertension is underestimated $[3,4]$. This over- and underestimation may be as large as $38 \%$ [5]. Another problem with most studies is that eligibility for drug treatment of hypertension is not taken into account. Most guidelines currently advise considering the overall cardiovascular risk of a patient before deciding to start drug treatment of hypertension [6,7]. When these considerations are taken into account to assess the number of untreated hypertensive patients that require drug treatment, the problem of uncontrolled blood pressure may not be as large as it seems [8]. Despite these limitations, and the consequent overestimation of the level of uncontrolled blood pressure, the level of poor blood pressure control remains unsatisfactorily high.

The article by Weinehall et al. [9] in this issue of the journal demonstrates that Sweden is no exception to this rule, and confirms previous reports from other countries indicating that many hypertensive patients have poorly controlled blood pressure and that uncontrolled blood pressure (treated and untreated) is strongly related to the risk of stroke. A nice feature of the study by Weinehall $e t a l$. is the combination of a cross-sectional and case-control study, allowing the estimation of both the prevalence of poor blood pressure control and its association with the risk of stroke in the population. Combining the prevalence and relative risk numerically results in the population attributable risk (PAR) (e.g. the proportion of strokes in the population that may be attributed to poor blood pressure control). Weinehall and colleagues find a PAR of $46 \%$ among hypertensive patients, suggesting that $46 \%$ of all strokes which occur among hypertensive subjects may be due to poor blood pressure control. A high proportion of patients with stroke attributable to poor blood pressure control has also been found in other countries, such as the UK, the Netherlands and the USA [10-12]. However, whether these strokes are all preventable remains uncertain because reduction of blood pressure does not necessarily mean a proportional reduction of the risk of stroke $[13,14]$. Although the call by Weinehall et al. for more specific attention to be paid to hypertension treatment by the medical profession should certainly be supported, it remains uncertain how to achieve population-based improvements in the treatment and control rates of hypertension. While the rule of halves may no longer be accurate, treatment and control rates of hypertension remain disappointingly low, despite nearly 30 years of extensive research into the problem, and numerous investigations of various intervention strategies aimed at improvement of different aspects in the management of hypertension [15]. 
Unfortunately, few of these interventions have been effective in achieving improved control of blood pressure. Multiple interventions at the level of patients, health-care providers (including physicians, pharmacists and nurses) and organizations (including hospitals and health-care insurers) are probably more effective than a single intervention by a health-care provider alone [16]. Therefore, an integrated effort, supported by healthcare providers, organizations and public health institutions, to improve the control of blood pressure should be undertaken. In addition, future research should be directed toward new and creative interventions, such as 'measurement-guided medication management' [17], and to pharmacogenetics which may help to individualize treatment according to the genetic profile of the patient, thereby reducing the occurrence of adverse effects and improving effectiveness [18]. These combined efforts will hopefully assure that the 'rule of halves' will not prevail for another 30 years.

\section{References}

1 Wilber JA, Barrow JG. Hypertension - a community problem. Am J Med 1972; 52:653-663.

2 Marques-Vidal P, Tuomilehto J. Hypertension awareness, treatment and control in the community: is the 'rule of halves' still valid? J Hum Hypertens 1997; 11:213-220.

3 Birkett NJ. The effect of alternative criteria for hypertension on estimates of prevalence and control. J Hypertens 1997; 15:237-244.

4 Klungel $\mathrm{OH}$, de Boer A, Paes AH, Nagelkerke NJ, Seidell JC, Bakker A. Estimating the prevalence of hypertension corrected for the effect of within-person variability in blood pressure. J Clin Epidemiol 2000; 53:1158-1163.

5 Klungel $\mathrm{OH}$, de Boer A, Paes AH, Nagelkerke NJ, Seidell JC, Bakker A. Influence of correction for within-person variability in blood pressure on the prevalence, awareness, treatment, and control of hypertension. Am $J$ Hypertens 2000; 13:88-91.

6 Guidelines Subcommittee. 1999 World Health Organization-International Society of Hypertension Guidelines for the Management of Hypertension. Guidelines Subcommittee. J Hypertens 1999; 17:151-183.

7 Joint National Committee on the Prevention D, Evaluation, and Treatment of High Blood Pressure. The Sixth Report of the Joint National Committee on the Prevention, Detection, Evaluation, and Treatment of High Blood Pressure. Arch Intern Med 1997; 157:2413-2446.

8 Klungel $\mathrm{OH}$, de Boer A, Paes AH, Seidell JC, Nagelkerke NJ, Bakker A. Undertreatment of hypertension in a population-based study in The Netherlands. J Hypertens 1998; 16:1371-1378.

9 Weinehall L, Öhgren B, Persson M, Stegmayr B, Boman K, Hallmans G Lindholm $\mathrm{LH}$. High remaining risk in poorly treated hypertension: the rule of halves still exists. J Hypertens 2002: 20:2081-2088.

10 Klungel $\mathrm{OH}$, Kaplan RC, Heckbert SR, Smith NL, Lemaitre RN, Longstreth WT Jr, et al. Control of blood pressure and risk of stroke among pharmacologically treated hypertensive patients. Stroke 2000; 31: $420-424$.

11 Klungel OH, Stricker BH, Paes AHP, Seidell JC, Bakker A, Voko Z, et al. Excess stroke among hypertensive men and women attributable to undertreatment of hypertension. Stroke 1999; 30:1312-1318.

12 Du X, Cruickshank K, McNamee R, Saraee M, Sourbutts J, Summers A, et al. Case-control study of stroke and the quality of hypertension control in north west England. BMJ 1997; 314:272-276.

13 Ekbom T, Dahlof B, Hansson L, Lindholm LH, Oden A, Schersten B, Wester PO. The stroke preventive effect in elderly hypertensives cannot fully be explained by the reduction in office blood pressure - insights from the Swedish Trial in Old Patients with Hypertension (STOP-Hypertension). Blood Press 1992; 1:168-172.

14 Sleight P, Yusuf S, Pogue J, Tsuyuki R, Diaz R, Probstfield J. Bloodpressure reduction and cardiovascular risk in HOPE study. Lancet 2001; 358:2130-2131.

15 Trilling JS, Froom J. The urgent need to improve hypertension care. Arch Fam Med 2000; 9:794-801.

16 Miller $\mathrm{NH}$, Hill M, Kottke T, Ockene IS. The multilevel compliance challenge: recommendations for a call to action. A statement for healthcare professionals. Circulation 1997; 95:1085-1090.

17 Burnier M, Schneider MP, Chiolero A, Stubi CL, Brunner HR. Electronic compliance monitoring in resistant hypertension: the basis for rational therapeutic decisions. J Hypertens 2001; 19:335-341.

18 Turner ST, Schwartz GL, Chapman AB, Hall WD, Boerwinkle E. Antihypertensive pharmacogenetics: getting the right drug into the right patient. J Hypertens Supp/ 2001; 19:1-11. 